\title{
EVALUACIÓN Y TRATAMIENTO DE EFLUENTES DEL REMOJO CONVENCIONAL Y ENZIMÁTICO DE PIELES, POR PRECIPITACIÓN DE PROTEÍNAS Y COAGULACIÓN
}

Yasmín Liseth Castañeda $C^{a^{*}}$, Rocío Vargas P. ${ }^{\mathrm{b}}$, Mary Flor Césare C ${ }^{\mathrm{a}}$, Lizardo Visitación F. ${ }^{\mathrm{a}}$

\section{RESUMEN}

Esta investigación evaluó y caracterizó efluentes del proceso de remojo convencional y enzimático de pieles, fue realizada a escala industrial con 20 pieles de ganado vacuno en las instalaciones de la empresa Helianthus S.A.C. Lima, Perú. Asimismo, se evaluó un sistema de tratamiento para dichos efluentes, constituido por precipitación de proteínas seguida de coagulación. Finalmente, el lodo seco de cada tratamiento se evaluó por separado para su potencial uso como fertilizante. La precipitación química de proteínas fue realizada aplicando un $\mathrm{pH}$ de 10,11 y 12, usando $\mathrm{KOH}$; mientras que en la coagulación se usaron dosis de 600 , 800 y $1000 \mathrm{mg} / \mathrm{L}$ de sulfato de aluminio al 17\%. En el remojo convencional, el sistema de tratamiento propuesto logró eficiencias de 70,3\%;84,9\%; 92,4\%;93,4\%; 61,8\%; 93,9\% y 99,6\%; mientras que en el remojo enzimático, 80,5\%; 83,8\%; 93,3\%; 93,8\%; 59,3\%; 93,5\% y $99,4 \%$ en términos de DBO, DQO, SST, AyG, NTK, S ${ }^{2-}$ y turbidez, respectivamente. El agua residual del proceso enzimático presentó mayor carga contaminante que el proceso convencional, probablemente relacionado a una mejor limpieza de las pieles por parte de la enzima Tanzyme RD04 utilizada. Para el tratamiento del efluente del remojo convencional y el enzimático, el pH óptimo de precipitación química fue 12 y la dosis óptima de coagulante, $800 \mathrm{mg} / \mathrm{L}$. Los lodos residuales obtenidos presentan un alto contenido orgánico.

Palabras clave: Remojo enzimático, remojo convencional, precipitación de proteína, coagulación, tratamiento.

\section{EVALUATION AND TREATMENT OF EFFLUENTS OF THE CONVENCIONAL AND THE ENZYMATIC LEATHER SOAKING PROCESSES, BY PROTEIN PRECIPITATION AND COAGULATION}

\begin{abstract}
This research consisted of the evaluation and characterization of wastewater generated during

a Centro de Investigación en Química, Toxicología y Biotecnología Ambiental del Departamento Académico de Química de la Facultad de Ciencias de la UNALM Lima - Perú.

*e-mail: ycastanedacalderon@gmail.com

${ }^{\mathrm{b}}$ Helianthus SAC, Laboratorio de desarrollo e Investigación curtiembre, Av. Guardia Civil \#314 Chorrillos - Lima - Perú
\end{abstract}


the leather soaking process, both in its conventional method and its enzymatic method. The experiments were conducted at an industrial scale at the Helianthus S.A.C. Company in Lima, using 20 cow hides. Likewise, a treatment process was evaluated for these effluents consisting of protein precipitation and was followed by coagulation. Finally, the dry sludge from each treatment method was evaluated separately for its potential use as fertilizer. The process for the chemical precipitation of proteins consisted of applying $\mathrm{KOH}$ until reaching $\mathrm{pH}$ values of 10, 11 and 12; while the coagulation process consisted of the application of doses of 600,800 and $1000 \mathrm{mg} / \mathrm{L}$ of aluminum sulphate $17 \%$. When using the conventional soaking process wastewater, the proposed treatment system achieved removal efficiencies of $70.3 \%, 84.9 \%, 92.4 \%, 93.4 \%, 61.8 \%, 93.9 \%$ and $99.6 \%$; when using the enzymatic soaking process wastewater, the system achieved $80.5 \%, 83.8 \%, 93.3 \%, 93.8 \%, 59.3 \% ; 93.5 \%$ and $99.4 \%$ removal efficiencies of BOD, COD, TSS, O\&F, TKN, $\mathrm{S}^{2-}$ and turbidity, respectively. The wastewater from the enzymatic soaking process had a higher level of pollutants than the one from conventional soaking, likely due to a better soaking of the hides with the Tanzyme RD04 enzyme which was used.

For the treatment of effluents from the conventional as well as the enzymatic soaking process, the optimum precipitation $\mathrm{pH}$ was 12 and the optimum coagulation dose for both effluents was $800 \mathrm{mg} / \mathrm{L}$. The organic content in the sludge was high.

Key words: Enzymatic soaking, conventional soaking, protein precipitation, coagulation, treatment.

\section{INTRODUCCIÓN}

La primera operación de una curtiembre es el remojo, en donde se tratan las pieles con agua $^{1}$. El remojo convencional utiliza de 100 a $1000 \%$ de agua con respecto al peso de piel salada $^{1,2}, \mathrm{NaOH}$ (basificante) para saponificar grasas, nonil fenol (tensoactivo) para acelerar la humectación de la piel, solubilizar suciedades y emulsificar grasas, $\mathrm{Na}_{2} \mathrm{~S}$ para favorecer el hinchamiento débil y penetración del agua a las fibras, bactericida (antiséptico) con la finalidad de eliminar bacterias y evitar perjuicios en la calidad final del cuero. También, busca la remoción de proteínas solubles en agua e insumos usados en la conservación de la piel $^{1,3}$. El nonil fenol es altamente tóxico, capaz de interferir con los sistemas de regulación de diferentes tipos de células y, tiene alta persistencia en el ambiente, incluso en algunos países está prohibido su uso ${ }^{4}$.

El uso de enzimas forma parte de una Producción Más Limpia ${ }^{1,2}$, estas sustituyen a tensoactivos, basificantes y sales neutras. La biotecnología se encuentra en continuo avance, diversos tipos de enzimas se vienen ensayando para el remojo, la enzima Tanzyme RD 04 usada en esta investigación es recomendada para una operación más rápida que el proceso convencional, una alta remoción de materia orgánica, una mayor actividad queratolítica, mediana actividad lipolítica y una baja actividad colagenolítica ${ }^{5}$. Se alcanzaron resultados exitosos utilizando esta tecnología en comparación con los procesos químicos convencionales de remojo ${ }^{5,6}$, 
obteniéndose mayor grado de rehidratación y limpieza debido a la eliminación de proteínas y grasas $^{6}$ y, menor tiempo de remojo requerido ${ }^{5,6}$, obteniendo una mejor calidad de cuero y menor impacto ambiental.

El efluente de remojo de pieles preservadas con sal tiene menor posibilidad de ser tratado por un sistema biológico convencional, a pesar de su alto contenido de proteínas, materia suspendida como suciedad, excremento y sangre ${ }^{7}$. Asimismo, debido a su elevado contenido de impurezas y un $\mathrm{pH}$ favorable para el crecimiento de bacterias, presenta condiciones propicias para su putrefacción ${ }^{1,7}$, siendo un efluente no idóneo para reciclaje, al menos no en su totalidad. Por tal motivo, requiere un sistema de tratamiento químico. Las proteínas del efluente pueden ser removidas con un $\mathrm{pH}$ óptimo de precipitación química, lo cual es corroborado por muchas investigaciones, las cuales han obtenido hasta $60 \%$ de remoción ${ }^{8}$. Asimismo, han reportado que se ha conseguido muy buenos resultados ${ }^{9}$ con el tratamiento físico químico mediante coagulación, constituyendo una buena alternativa de tratamiento para la remoción de sólidos y materia orgánica del efluente de remojo.

El objetivo de la presente investigación fue evaluar la calidad del efluente para un remojo convencional (con químicos) y un remojo alternativo (con enzimas). Así como evaluar un sistema de tratamiento mediante precipitación de proteínas con ajuste de $\mathrm{pH}$, seguido de un proceso de coagulación para los efluentes de ambos remojos, con la finalidad de que cumplan con los Valores Máximo Permisibles (VMA) de las descargas de aguas residuales no domésticas en el sistema de alcantarillado sanitario indicados en el D.S. 001-2015 VIVIENDA. Se evaluó también el potencial uso como fertilizante de los lodos residuales producidos por el sistema de tratamiento propuesto.

\section{PARTE EXPERIMENTAL}

\section{Materiales y métodos}

\section{Procedimiento de proceso de remojo}

Se evaluaron dos tipos de remojo, convencional y alternativo, previa preservación de pieles con sal. El remojo convencional considera las condiciones promedio llevadas a cabo en las curtiembres del Perú; mientras que el remojo alternativo utiliza enzimas microbianas en sustitución de tensoactivos, desengrasantes y basificantes. Las fórmulas químicas para la realización de ambos remojos se indican en la tabla 1, las cuales fueron proporcionadas por la empresa Helianthus S.A.C. 
Tabla 1. Materias primas utilizadas en el remojo convencional y en el enzimático.

\begin{tabular}{|c|c|c|c|c|}
\hline \multirow[b]{2}{*}{ Etapa } & \multirow[b]{2}{*}{ Productos } & \multicolumn{2}{|c|}{ Remojo } & \multirow[b]{2}{*}{ Tiempo } \\
\hline & & Conv. & Enz. & \\
\hline \multirow[t]{2}{*}{$\begin{array}{l}\text { Lavado inicial } \\
\text { del remojo }\end{array}$} & Agua $\left(28^{\circ} \mathrm{C}\right)$ & 200,0 & 200,0 & $60^{\prime}$ \\
\hline & $\operatorname{Agua}\left(28^{\circ} \mathrm{C}\right)$ & 200,0 & 100,0 & \multirow{6}{*}{$\begin{array}{l}6 \text { horas: } \\
5 \text { ' mov. / } \\
25 \text { ' parada }\end{array}$} \\
\hline \multirow{5}{*}{ Remojo principal } & $\mathrm{NaOH}$ & 0,2 & - & \\
\hline & Tensoactivo Nonil fenol & 0,3 & - & \\
\hline & $\mathrm{Na}_{2} \mathrm{~S}$ & 0,1 & - & \\
\hline & Bactericida & 0,1 & 0,1 & \\
\hline & Enzima Tanzyme RD 04 & - & 0,2 & \\
\hline $\begin{array}{l}\text { Lavado final } \\
\text { del remojo }\end{array}$ & Agua $\left(28^{\circ} \mathrm{C}\right)$ & 100,0 & 100,0 & $15^{\prime}$ \\
\hline
\end{tabular}

\section{Caracterización de efluentes de los remojos convencional y enzimático}

Los efluentes de los remojos convencional y enzimático fueron colectados como resultado de una prueba a escala industrial con 20 pieles de ganado vacuno, cada uno, realizada en un botal en las instalaciones de la empresa Helianthus S.A.C. Lima, Perú. Posteriormente, fueron caracterizados. En la tabla 2 se puede observar los parámetros analizados.

Se efectuaron ajustes a los valores de DQO, el alto contenido de $\mathrm{Cl}^{-}$generó grandes interferencias, por ello se realizaron blancos de $\mathrm{Cl}^{-}$.

Tabla 2. Parámetros analizados a los efluentes de remojo.

\begin{tabular}{|c|c|c|c|}
\hline Parámetros & Unid. & & Método \\
\hline Turbidez & NTU & & $20^{\mathrm{va}}$ ed. $2130 \mathrm{~B}$ M. Nefelométrico. \\
\hline $\mathrm{EC}$ & $\mathrm{mS} / \mathrm{cm}$ & & M. Electrométrico \\
\hline SST & $\mathrm{mg} / \mathrm{L}$ & & $20^{\mathrm{va}}$ ed. 2540 D SST secados a $103-105^{\circ} \mathrm{C}$. \\
\hline SS & $\mathrm{ml} / \mathrm{L}$ & & $20^{\mathrm{va}}$ ed. $2540 \mathrm{~F}$ Sólidos sedimentables. \\
\hline $\mathrm{DBO}_{5}$ & $\mathrm{mg} / \mathrm{L}$ & & $20^{\text {va }}$ ed. 5210 B Prueba ROB de 5 días. \\
\hline DQO & $\mathrm{mg} / \mathrm{L}$ & & $20^{\mathrm{va}}$ ed. 5220 D Reflujo cerrado, M. Colorimétrico. \\
\hline pH & - & Estandar & $20^{\mathrm{va}}$ ed. $4500-\mathrm{H}^{+}$Electrométrico. \\
\hline AyG & $\mathrm{mg} / \mathrm{L}$ & Metodos & $20^{\mathrm{va}}$ ed. 5520 B Partición - gravimetría. \\
\hline $\mathrm{S}^{2-}$ & $\mathrm{mg} / \mathrm{L}$ & & $20^{\mathrm{va}}$ ed. $4500-\mathrm{S}^{2-}$ E Yodométrico. \\
\hline $\mathrm{SO}_{4}{ }^{2-}$ & $\mathrm{mg} / \mathrm{L}$ & & $20^{\mathrm{va}}$ ed. $4500-\mathrm{SO}_{4}{ }^{2-} \mathrm{E}$ Turbidimétrico. \\
\hline $\mathrm{NH}_{3}$ & $\mathrm{mg} / \mathrm{L}$ & & $20^{\mathrm{va}}$ ed. $4500-\mathrm{NH}_{3}$ E Titulométrico. \\
\hline NTK & $\mathrm{mg} / \mathrm{L}$ & & $20^{\text {va }}$ ed. $4500-\mathrm{N}_{\text {org }}$ C Semi-micro- Kjeldahl. \\
\hline $\mathrm{Cl}^{-}$ & $\mathrm{mg} / \mathrm{L}$ & & $20^{\mathrm{va}}$ ed. $4500-\mathrm{Cl}^{-} \mathrm{B}$ Argentométrico. \\
\hline $\mathrm{Cr}^{+6}$ & $\mathrm{mg} / \mathrm{L}$ & & $20^{\mathrm{va}}$ ed. $3500-\mathrm{Cr} \mathrm{B}$ Abs. Atómica para Cr total. \\
\hline $\mathrm{Hg}$ & $\mathrm{mg} / \mathrm{L}$ & & $\begin{array}{l}21^{\text {ra }} \text { ed. } 3112-\mathrm{B} \text { Espectrométrico Abs. Atómica de } \\
\text { vapor frío. }\end{array}$ \\
\hline $\begin{array}{l}\text { Metales } \\
\text { Totales }\end{array}$ & $\mathrm{mg} / \mathrm{L}$ & EPA & 200.7 (1994). \\
\hline
\end{tabular}




\section{Sistema de tratamiento propuesto de efluentes}

El sistema de tratamiento propuesto para los efluentes de los procesos de remojo convencional y enzimático se desarrolló en dos etapas. Cada remojo presentó tres baños, es decir, tres efluentes; el tratamiento fue realizado al efluente mezcla de los tres baños. La primera etapa consistió en la precipitación de proteínas por cambio de $\mathrm{pH}$ utilizando $\mathrm{HCl}$ e $\mathrm{KOH}$ (grado reactivo), se ensayaron $\mathrm{pH}$ ácidos de 2, 3 y 5 y, básicos de 10, 11 y 12 . Se evaluó la influencia del pH sobre la remoción de proteína en términos de NTK, DQO, SST y turbidez. Se determinó el pH óptimo de precipitación y a este se le realizaron análisis adicionales de AyG, $\mathrm{S}^{2-}$ y SS.

El sobrenadante de la precipitación de proteínas fue sifonado hacia otros recipientes donde se ajustó a pH neutro. Posteriormente, fue sometido a coagulación mediante el uso de test de jarras bajo las condiciones recomendadas para agua residual industrial ${ }^{10}$. Siendo las dosis de $\mathrm{Al}_{2}\left(\mathrm{SO}_{4}\right)_{3}$ aplicadas: 600, 800 y $1000 \mathrm{mg} / \mathrm{L}$. Posteriormente, se evaluó la influencia de las dosis de aluminio en la remoción de contaminantes en términos de NTK, DQO, SST y turbidez. Se determinó la dosis óptima de coagulación y a esta se le realizaron análisis adicionales de $\mathrm{AyG}, \mathrm{S}^{2-}$ y SS.

Para ambos tratamientos se realizaron pruebas por triplicado.

\section{Análisis estadístico de los resultados}

El software utilizado fue IBM SPSS Statistics. Se planteó un Diseño Completamente al Azar (DCA). Para ambos tipos de remojo y para los dos tipos de tratamientos consecutivos aplicados, se realizó validación estadística evaluada por ANOVA (análisis de variancia) para analizar si los pH o las dosis de aluminio aplicados influyen en los parámetros analizados. Se utilizó la Prueba de Tukey para evaluar la significancia entre los tratamientos realizados. Adicionalmente, se evaluó el Coeficiente de Variabilidad en términos porcentuales entre los tratamientos para verificar la dispersión correspondiente a una serie de datos respecto al valor medio.

\section{Evaluación del potencial como fertilizante de los lodos provenientes del sistema de tratamiento propuesto}

Los lodos residuales obtenidos en los tratamientos con $\mathrm{pH}$ óptimo de precipitación y dosis óptima de coagulación para los efluentes del remojo convencional y el enzimático, fueron secados y pulverizados, posteriormente analizados por su potencial como fertilizante y fueron comparados con el vermicompost. El vermicompost es un abono de establo, orgánico producido como el compost por la alimentación de materiales de desechos orgánicos por parte de las lombrices. Este tipo de abono contiene una fuente de nutrientes en equilibrio que es preferido para la agricultura ecológica y respetuosa con el medio ambiente ${ }^{3}$. Los parámetros evaluados se muestran en la tabla 3. 
Tabla 3. Parámetros analizados al lodo residual.

\begin{tabular}{lcc}
\hline \multicolumn{1}{c}{ Parámetros } & Abrev. & Unid. \\
\hline Humedad & $\mathrm{H}$ & $\%$ \\
Ceniza & - & $\% \mathrm{MS}$ \\
Carbono orgánico total & $\mathrm{COT}$ & $\% \mathrm{MS}$ \\
Nitrógeno & $\mathrm{N}$ & $\% \mathrm{MS}$ \\
Relación carbono-nitrógeno & $\mathrm{C} / \mathrm{N}$ & - \\
Contenido de potasio & $\mathrm{P}_{2} \mathrm{O}_{5}$ & $\%$ \\
Contenido de fósforo & $\mathrm{K}_{2} \mathrm{O}$ & $\%$ \\
\hline
\end{tabular}

\section{RESULTADOS Y DISCUSIÓN}

\section{Caracterización de efluentes de los remojos convencional y enzimático}

Los resultados de la caracterización de efluentes de los remojos convencional y enzimático, son presentados en la tabla 4.

Para el efluente "lavado inicial del remojo convencional", los AyG (228 mg/L), DQO (2227 $\mathrm{mg} / \mathrm{L})$ y NTK $(158,1 \mathrm{mg} / \mathrm{L})$ fueron menores a los indicados por Bornhardt, Vidal y Torres (395 y 2890, $215 \mathrm{mg} / \mathrm{L}$, respectivamente $)^{11}$; mientras que los $\mathrm{SO}_{4}^{2-}(78 \mathrm{mg} / \mathrm{L})$ y $\mathrm{DBO}_{5}(620$ $\mathrm{mg} / \mathrm{L}$ ) fueron mayores a los reportados por dichos autores $\left(60\right.$ y $390 \mathrm{mg} / \mathrm{L}$, respectivamente) ${ }^{11}$. Los SST (1208 mg/L) y $\mathrm{NH}_{3}(77,6 \mathrm{mg} / \mathrm{L})$ resultaron menores a los dados por Méndez, Vidal, Lorber y Márquez ${ }^{12}\left(1500\right.$ y $86 \mathrm{mg} / \mathrm{L}$, respectivamente); mientras que el $\mathrm{S}^{2-}(14,1 \mathrm{mg} / \mathrm{L})$ fue mucho mayor y, el $\mathrm{pH}(7)$ muy similar a los reportados por dicho autor $(0,003 \mathrm{mg} / \mathrm{L} \mathrm{y}$ $6,9$, respectivamente $)^{12}$. Este efluente, en términos de SST, DBO y DQO, es superado en 1,$87 ; 0,37$ y 0,17 veces más, respectivamente. por el efluente del lavado inicial del remojo enzimático. Las diferencias en las concentraciones entre ambos efluentes y las encontradas con otros autores, se atribuyen a las características de la piel, ya que el único insumo utilizado en esta etapa, además de la piel, fue el agua. Por lo tanto, las pieles usadas en el remojo enzimático presentaron mayor grado de ensuciamiento pero se mantuvieron en mejor grado de conservación $\left(\mathrm{NH}_{3}=56,35 \mathrm{mg} / \mathrm{L}\right)$ que las usadas en el remojo convencional $\left(\mathrm{NH}_{3}=77,6\right)$. Los parámetros $\mathrm{EC} \mathrm{y} \mathrm{Cl-,} \mathrm{están} \mathrm{relacionados} \mathrm{directamente} \mathrm{con} \mathrm{la} \mathrm{conservación} \mathrm{y,} \mathrm{su} \mathrm{variación}$ se debe al grado de absorción del agua en la piel.

Para el efluente "remojo principal convencional", la DQO (13807 mg/L) fue similar a lo indicado por Bornhardt et. $a l^{11}(13780 \mathrm{mg} / \mathrm{L})$, sin embargo los $\mathrm{SO}_{4}^{2-}(237,7 \mathrm{mg} / \mathrm{L})$ y NTK $(660,3 \mathrm{mg} / \mathrm{L})$ fueron menores $\mathrm{y}, \operatorname{los} \mathrm{Cl}^{-}(17073 \mathrm{mg} / \mathrm{L})$ mayores a lo indicado por dicho autor (350, 795 y $11675 \mathrm{mg} / \mathrm{L}$, respectivamente). $\mathrm{El} \mathrm{pH}(9)$ y $\mathrm{NH}_{3}(96,7 \mathrm{mg} / \mathrm{L})$ resultaron similares a lo reportado por Méndez et.al ${ }^{12}$ (8,7 y 18 a $210 \mathrm{mg} / \mathrm{L}$, respectivamente), mientras que los $\mathrm{S}^{2-}(37,6 \mathrm{mg} / \mathrm{L})$ y los SST $(5621 \mathrm{mg} / \mathrm{L})$ fueron superiores (3 y $4140 \mathrm{mg} / \mathrm{L}$, respectivamente) $\mathrm{y}$, la $\mathrm{DBO}_{5}(1000 \mathrm{mg} / \mathrm{L})$ menor a lo indicado por dicho autor $(2870 \mathrm{mg} / \mathrm{L})$. Este efluente en términos de $\mathrm{SST}, \mathrm{DBO}, \mathrm{DQO}, \mathrm{SO}_{4}^{2-}, \mathrm{NH}_{3}$ y NTK es superado en 0,$8 ; 0,35 ; 0,11 ; 0,83$; 0,65 y 0,31 veces más, respectivamente, por el efluente de remojo principal enzimático. El tensoactivo generó mayor emulsión de grasas lo que se traduce en un mayor contenido de AyG en el baño; mientras que la enzima realizó un mejor ataque a proteínas y un mejor remojo de la piel, generando mayor carga contaminante en el baño. 
Los valores de NTK $(167,07 \mathrm{mg} / \mathrm{L})$ y SST $(1687 \mathrm{mg} / \mathrm{L})$ fueron similares a lo reportado por Bornhardt et. $a l^{11}(175 \mathrm{y} 1470 \mathrm{mg} / \mathrm{L}$, respectivamente); mientras que el DQO (3874 $\mathrm{mg} / \mathrm{L}), \mathrm{SO}_{4}^{2-}(139,2 \mathrm{mg} / \mathrm{L}), \mathrm{NH}_{3}(75,1)$ y el $\mathrm{pH}(8,85)$ resultaron mayores $(3000,35,3 \mathrm{mg} / \mathrm{L}$ y 7,6, respectivamente) y, el valor de AyG $(196 \mathrm{mg} / \mathrm{L})$ fue menor a lo reportado por dicho autor $(545 \mathrm{mg} / \mathrm{L})$. Este efluente en términos de SST, DQO, AyG y NTK es superado en 1,8; 0,$75 ; 0,54$ y 0,72 veces más, respectivamente, por el efluente del lavado final del remojo enzimático. El poder limpiador de la enzima utilizada se impuso sobre el del tensoactivo, generando un mayor ataque a proteínas (actividad queratolítica) y grasas (actividad lipolítica) que generaron mayor carga contaminante en el efluente.

En lo que respecta al efluente mezcla del remojo convencional, el $\mathrm{pH}(8,2), \mathrm{NH}_{3}(84,7 \mathrm{mg} / \mathrm{L})$ y NTK $(360,7 \mathrm{mg} / \mathrm{L})$ fueron similares a lo reportado por Lefebvrea, Vasudevan, Torrijosa, Thanasekaran y Moletta $^{13}$ (7,8 y 90 y $350 \mathrm{mg} / \mathrm{L}$, respectivamente); mientras que la DQO $(7188 \mathrm{mg} / \mathrm{L})$ fue menor a lo indicado por dichos autores $(8280 \mathrm{mg} / \mathrm{L})$. Los SST $(3069,1$ $\mathrm{mg} / \mathrm{L})$ resultaron semejantes a lo indicado por Ilou, Souabi y Digua ${ }^{14}(3000 \mathrm{mg} / \mathrm{L})$; mientras que los $\mathrm{S}^{2-}(26,3)$ fueron casi el doble de lo indicado por dichos autores $(13,43 \mathrm{mg} / \mathrm{L})$. La $\mathrm{DBO}_{5}(908 \mathrm{mg} / \mathrm{L})$ fue similar a lo reportado por Iyappan, Boopathy, Suguna, Ranganathan y Vedaraman ${ }^{15}(1016 \mathrm{mg} / \mathrm{L})$; los AyG $(323,4 \mathrm{mg} / \mathrm{L})$ se encontraron en el rango dado por Miller, Gagnet y Worde $^{16}(200$ a $400 \mathrm{mg} / \mathrm{L})$. Este efluente en términos de SST, DQO y NTK es superado en 1,$8 ; 0,75$ y 0,72 veces más por el efluente del lavado final del remojo enzimático. El mayor contenido de NTK en el remojo enzimático se debe a un mejor ataque a las proteínas de la piel generada por las enzimas ${ }^{5}$. El mayor contenido de AyG en el remojo convencional se debe a un mayor ataque de lípidos generado por la acción del nonil fenol (tensoactivo) y el $\mathrm{NaOH}$. La concentración de $\mathrm{S}^{2-}$ superior en el remojo convencional se debe al uso de $\mathrm{Na} 2 \mathrm{~S}$. En términos generales el empleo de enzimas genera pieles mejor remojadas, lo que se traduce en una mejor limpieza de las mismas y mayor carga contaminante en el efluente.

Tabla 4. Caracterización de los efluentes del remojo convencional y enzimático.

\begin{tabular}{|c|c|c|c|c|c|c|c|c|}
\hline \multirow[b]{2}{*}{ Parámet.* } & \multicolumn{4}{|c|}{ Remojo Convencional } & \multicolumn{4}{|c|}{ Remojo Enzimático } \\
\hline & $\begin{array}{l}\text { Lav. } \\
\text { Inicial }\end{array}$ & $\begin{array}{l}\text { Remojo } \\
\text { Princip. }\end{array}$ & $\begin{array}{l}\text { Lav. } \\
\text { Final }\end{array}$ & $\begin{array}{l}\text { Efluente } \\
\text { mezcla }\end{array}$ & $\begin{array}{l}\text { Lav. } \\
\text { Inicial }\end{array}$ & $\begin{array}{l}\text { Remojo } \\
\text { Princip. }\end{array}$ & $\begin{array}{l}\text { Lav. } \\
\text { Final }\end{array}$ & $\begin{array}{c}\text { Efluente } \\
\text { mezcla }\end{array}$ \\
\hline $\mathrm{T}$ & 22,0 & 22,0 & 21,0 & - & 24,0 & 24,3 & 25,0 & - \\
\hline Turbidez & - & - & - & 3165,0 & - & - & - & 4470,0 \\
\hline $\mathrm{P}$ & - & - & - & 29,32 & - & - & - & 51,05 \\
\hline $\mathrm{EC}$ & 52,6 & 36,2 & 12,0 & 37,9 & 60,1 & 63,4 & 24,2 & 51,9 \\
\hline SST & 1208,0 & 5621,0 & 1687,0 & 3069,1 & 3463,0 & 10137,0 & 4738,0 & 5450,3 \\
\hline SS & N.D. $* *$ & N.D.** & N.D.** & N.D. $* *$ & N.D.** & N.D.** & N.D.** & N.D. $* *$ \\
\hline $\mathrm{DBO}_{5}$ & 620,0 & 1000,0 & 1300,0 & 908,0 & 850,0 & 1350 & 1050,0 & 1025,0 \\
\hline DQO & 2227,0 & 13807,0 & 3874,0 & 7188,0 & 2618,2 & 15401 & 6784,9 & 6855,0 \\
\hline $\mathrm{pH}$ & 7,0 & 9,0 & 8,9 & 8,2 & 7,4 & 7,2 & 7,5 & 7,4 \\
\hline AyG & 228,0 & 482,5 & 196,0 & 323,4 & 84,0 & 428,0 & 302,0 & 224,5 \\
\hline $\mathrm{S}^{2-}$ & 14,1 & 37,6 & 28,2 & 26,3 & 10,6 & 18,8 & 21,9 & 15,5 \\
\hline $\mathrm{SO}_{4}{ }^{2-}$ & 78,0 & 237,7 & 139,2 & 154,1 & 85,8 & 436,1 & 143,9 & 187,9 \\
\hline $\mathrm{NH}_{3}$ & 77,60 & 96,7 & 75,1 & 84,7 & 56,4 & 159,7 & 66,9 & 84,8 \\
\hline NTK & 158,1 & 660,3 & 167,1 & 360,7 & 201,1 & 865,3 & 286,9 & 388,6 \\
\hline $\mathrm{Cl}^{-}$ & 24144,0 & 17073,0 & 5476,0 & 17582,0 & 27592,9 & 29317 & 9082,2 & 23906,6 \\
\hline
\end{tabular}


Con respecto al contenido de metales del efluente mezcla del remojo convencional, Ilou et.al ${ }^{14}$ reportó valores de: 0,$004 ; 0,202 ; 0,12 ; 8,27 ; 0,01 ; 0,007 ; 0,73$ y $1,85 \mathrm{mg} / \mathrm{L}$, para: cadmio, cromo, cobre, hierro, mercurio, níquel, plomo y zinc, respectivamente; mientras que los valores encontrados en la presente investigación fueron: 0,$082 ; 0,357 ; 0,039 ; 1,89$; $<0,0001 ; 0,0048 ; 0,081$ y 0,587 , respectivamente (tabla 5 ). La concentración de hierro encontrada es baja, este metal tiene una relación muy estrecha con la sangre eliminada en el baño del remojo (en algunos lugares de beneficio del ganado vacuno, lavan las pieles después de la matanza, reduciendo la sangre). En general, las concentraciones de metales están relacionadas a la alimentación del ganado vacuno, fuentes de agua y pastizales con presencia de metales en donde ellos han sido criados. No se evidencia valores altos de ninguno de los metales analizados a diferencia del sodio, valor alto producto de la conservación previa con sal industrial.

Tabla 5. Caracterización de metales en los efluentes mezcla de los remojos convencional y enzimático.

\begin{tabular}{lcc}
\hline \multirow{2}{*}{ Parámetro* } & \multicolumn{2}{c}{ Efluente mezcla remojo } \\
\cline { 2 - 3 } & Convencional & Enzimático \\
\hline $\mathrm{Cr}{ }^{+6}$ & $<0,01$ & $<0,01$ \\
$\mathrm{Hg}$ & $<0,0001$ & 0,0009 \\
$\mathrm{Al}$ & 0,965 & 1,406 \\
$\mathrm{Sb}$ & 0,013 & 0,081 \\
$\mathrm{As}$ & $<0,005$ & 0,024 \\
$\mathrm{Ba}$ & 0,0536 & 0,0864 \\
$\mathrm{Be}$ & $<0,0002$ & $<0,0002$ \\
$\mathrm{Bi}$ & 0,023 & 0,025 \\
$\mathrm{~B}$ & 0,299 & 0,369 \\
$\mathrm{Cd}$ & 0,0082 & 0,0196 \\
$\mathrm{Ca}$ & 229,4 & 344,5 \\
$\mathrm{Ce}$ & $<0,004$ & 0,007 \\
$\mathrm{Co}$ & 0,003 & 0,006 \\
$\mathrm{Cu}$ & 0,039 & 0,717 \\
$\mathrm{Cr}$ & 0,357 & 0,565 \\
$\mathrm{Sn}$ & 0,162 & 0,241 \\
$\mathrm{Sr}$ & 1,69 & 2,64 \\
$\mathrm{Fe}$ & 1,891 & 2,656 \\
$\mathrm{Li}$ & 0,131 & 0,130 \\
$\mathrm{~K}$ & 136,4 & 178,7 \\
$\mathrm{Na}$ & $>20,0$ & $>20,0$ \\
$\mathrm{Ti}$ & 0,013 & 0,033 \\
$\mathrm{~V}$ & 0,0031 & 0,0078 \\
$\mathrm{Zn}$ & 0,587 & 0,773 \\
$\mathrm{Mg}$ & 21,54 & $>50,0$ \\
$\mathrm{Mn}$ & 0,083 & 0,192 \\
$\mathrm{Mo}$ & 0,0111 & 0,0976 \\
$\mathrm{Ni}$ & 0,0048 & 0,0089 \\
$\mathrm{Ag}$ & $<0,0009$ & 0,0114 \\
$\mathrm{~Pb}$ & 0,081 & 0,112 \\
$* \mathrm{Todos}$ los parámetros & $s 00$ dados en $\mathrm{mg} / \mathrm{L}$ \\
& &
\end{tabular}




\section{Influencia del pH en el tratamiento y precipitación de proteína}

La precipitación en medio ácido no consiguió una adecuada desestabilización de proteínas, lo cual indica que el punto isoeléctrico de la mezcla de proteínas del efluente mezcla para ambos remojos no se encontraba en medio ácido, generando una pobre formación de coágulos.

Las máximas remociones de eficiencia obtenidas para el efluente mezcla del remojo convencional fueron 88,$4 ; 56,1 ; 43,2$ y $26,4 \%$ (tabla 7 ); mientras que para el efluente mezcla del remojo enzimático, 97,8; 81,$3 ; 57,9$ y $31,2 \%$ (tabla 7 ) en términos de turbidez, SST, DQO y NTK, respectivamente. La eficiencia alcanzada en SST para remojo convencional es similar a lo reportado por Mijaylova, Moeller y Juárez ${ }^{17}(60 \%)$ para el baño de curtido. Las eficiencias obtenidas para DQO (tabla 7) son semejantes a los 44,3\% reportados por Córdova $^{18}$ para un pH de 10,71 del efluente de curtido. La eficiencia de NTK para ambos remojos (tabla 7 ) es menor a lo indicado por dicho autor $(59,75 \%)$ debido a que el efluente de curtido presentó mayor proteína en el baño. En general, las concentraciones de los parámetros evaluados disminuyen en los efluentes de ambos remojos cuando se incrementa el $\mathrm{pH}$, alcanzando remociones máximas a $\mathrm{pH} 12$ (tabla 7). La mezcla de proteínas cuyo punto isoeléctrico es cercano a 12 , ha sido removida en su totalidad o en gran proporción del efluente para ambos tipos de remojo, limitando su solubilidad y facilitando su precipitación. El valor aún alto de nitrógeno en el efluente (tabla 7), indica que quedan en disolución las proteínas cuyos valores de $\mathrm{pH}$ isoeléctricos se hallen por debajo o por encima de 12 .

Tabla 6. Caracterización de metales en los efluentes mezcla de los remojos convencional y enzimático.

\begin{tabular}{clcccccccc}
\hline & & \multicolumn{7}{c}{ Valor de $\mathrm{pH}$} \\
\cline { 4 - 9 } Efluente & Parámetros* & C. & \multicolumn{2}{c}{10} & \multicolumn{2}{c}{11} & \multicolumn{2}{c}{12} \\
\cline { 4 - 9 } & & inicial & C. & E.R. & C. & E.R. & C. & E.R. \\
& & Final & $* *$ & Final & $* *$ & Final & $* *$ \\
\hline \multirow{2}{*}{ Remojo } & Turbidez & 3165,0 & 829,0 & 73,8 & 496,3 & 84,3 & 368,0 & 88,4 \\
Conv. & SST & 3069,1 & 2353,0 & 23,3 & 2011,0 & 34,5 & 1348,0 & 56,1 \\
& NTK & 7188,0 & 5843,0 & 18,7 & 4640,0 & 35,4 & 4083,0 & 43,2 \\
& 360,7 & 319,7 & 11,4 & 297,4 & 17,6 & 265,4 & 26,4 \\
\hline \multirow{2}{*}{ Remojo } & Turbidez & 4470,0 & 550,1 & 87,7 & 390,7 & 91,3 & 97,2 & 97,8 \\
Enz. & SST & 5450,3 & 1371,0 & 74,8 & 1322,0 & 75,7 & 1021,0 & 81,3 \\
& NTK & 6855,0 & 4030,0 & 41,2 & 3843,0 & 43,9 & 2883,0 & 57,9 \\
& 388,6 & 319,8 & 17,7 & 308,4 & 20,6 & 267,4 & 31,2 \\
\hline
\end{tabular}

* Todos los parámetros a excepción de la turbidez (NTU) son dados en mg/L.

** E.R: eficiencia de remoción en \%. 


\section{Influencia de la dosis de aluminio en el tratamiento}

Las máximas remociones de eficiencia obtenidas para el efluente mezcla del remojo convencional fueron 96,$8 ; 82,7 ; 73,5$ y $48,1 \%$ (tabla 8 ); mientras que para el efluente mezcla del remojo enzimático, 73,4; 64,4; 60,7 y 40,8\% (tabla 8) en términos de turbidez, SST, DQO y NTK, respectivamente. Las eficiencias alcanzadas en turbidez, DQO y SST fueron similares a lo reportado por Cerón ${ }^{9}(94,45 ; 58,5$ y 89,2\%, respectivamente) para el efluente de remojo con $250 \mathrm{mg} / \mathrm{L}$ de $\mathrm{FeCl}_{3}$. En términos generales, las eficiencias obtenidas por una dosis mayor a $800 \mathrm{mg} / \mathrm{L}$ de $\mathrm{Al}_{2}\left(\mathrm{SO}_{4}\right)_{3}$ al $17 \%$ disminuyen (tabla 8 ), lo que se asocia a una resuspensión de los coloides a causa de un exceso en la dosificación del coagulante. A partir de estas observaciones, la dosis de $800 \mathrm{mg} / \mathrm{L}$ fue seleccionada como la dosis óptima de coagulación para ambos remojos. De los valores obtenidos (tabla 8), se observa que en el efluente tratado aún existe alto contenido orgánico disuelto.

Tabla 7. Influencia de la dosis de aluminio en el tratamiento

\begin{tabular}{|c|c|c|c|c|c|c|c|c|}
\hline \multirow{3}{*}{ Efluente } & \multirow{3}{*}{ Parámetros } & \multirow{3}{*}{$\begin{array}{c}\text { C. } \\
\text { inicial }\end{array}$} & \multicolumn{6}{|c|}{ Dosis de aluminio (mg/L) } \\
\hline & & & \multicolumn{2}{|c|}{600} & \multicolumn{2}{|c|}{800} & \multicolumn{2}{|c|}{1000} \\
\hline & & & $\begin{array}{c}\text { C. } \\
\text { Final }\end{array}$ & $\begin{array}{c}\text { E.R. } \\
* *\end{array}$ & $\begin{array}{c}\text { C. } \\
\text { Final }\end{array}$ & $\begin{array}{c}\text { E.R. } \\
* *\end{array}$ & $\begin{array}{c}\text { C. } \\
\text { Final }\end{array}$ & $\begin{array}{c}\text { E.R. } \\
* *\end{array}$ \\
\hline & Turbidez & 368,0 & 25,8 & 93,0 & 11,8 & 96,8 & 18,17 & 95,1 \\
\hline Remojo & SST & 1348,0 & 545,0 & 59,6 & 232,8 & 82,7 & 421,1 & 68,8 \\
\hline \multirow[t]{3}{*}{ Conv. } & DQO & 4083,0 & 1963,0 & 51,9 & 1083,0 & 73,5 & 1533,0 & 62,5 \\
\hline & NTK & 265,4 & 180,9 & 31,8 & 137,7 & 48,1 & 164,6 & 38,0 \\
\hline & Turbidez & 97,2 & 37,0 & 61,9 & 25,9 & 73,4 & 30,8 & 68,3 \\
\hline Remojo & SST & 1021,0 & 464,0 & 54,6 & 363,0 & 64,4 & 405,0 & 60,3 \\
\hline \multirow[t]{2}{*}{ Enz. } & DQO & 2883,0 & 2043,0 & 29,1 & 1133,0 & 60,7 & 1720,0 & 40,3 \\
\hline & NTK & 267,4 & 171,0 & 36,1 & 158,3 & 40,8 & 169,0 & 36,8 \\
\hline
\end{tabular}

\section{Sistema de tratamiento de efluentes propuesto}

Para ambos tipos de remojos, el pH óptimo fue 12 (tabla 7) y la dosis óptima de aluminio fue $800 \mathrm{mg} / \mathrm{L}$ (tabla 8). Con el sistema de tratamiento propuesto se obtienen remociones en $\mathrm{S}^{2-}$ de $93,9 \%$ y $93,5 \%$ para el remojo convencional y el enzimático, respectivamente (tabla 9). Asimismo, las eficiencias totales obtenidas por el sistema de tratamiento propuesto fueron similares, sin variación significativa. Se obtuvieron remociones de $\mathrm{DBO}_{5}$ por encima del $70 \%$ para ambos remojos (tabla 9).

Las concentraciones de los parámetros analizados obtenidas posteriores al tratamiento propuesto (tabla 9), de los parámetros analizados, cumplen con los Valores Máximo Permisibles (VMA) indicados en el D.S. 001-2015 VIVIENDA, a excepción de la DQO que en ambos remojos se requerirá un sistema de pulimento del efluente ya que su límite según normativa es $1000 \mathrm{mg} / \mathrm{L}$. 
Tabla 8. Caracterización del sistema de tratamiento de efluentes propuesto

\begin{tabular}{|c|c|c|c|c|c|c|c|c|}
\hline \multirow[b]{2}{*}{ Parámet. } & \multicolumn{4}{|c|}{ Remojo convencional } & \multicolumn{4}{|c|}{ Remojo enzimático } \\
\hline & $\begin{array}{l}\text { Efluente } \\
\text { mezcla }\end{array}$ & $\begin{array}{c}\text { Trat. } 1 \\
(* * *)\end{array}$ & $\begin{array}{l}\text { Trat. } 2 . \\
(* * * *)\end{array}$ & $\begin{array}{c}\text { E.R. } \\
* *\end{array}$ & $\begin{array}{l}\text { Efluente } \\
\text { mezcla }\end{array}$ & $\begin{array}{c}\text { Trat. } 1 \\
(* * *)\end{array}$ & $\begin{array}{l}\text { Trat. } 2 . \\
(* * * *)\end{array}$ & $\begin{array}{c}\text { E.R. } \\
* *\end{array}$ \\
\hline $\mathrm{DBO}_{5}$ & 908,0 & 500,0 & 270,0 & 70,3 & 1025,0 & 600,0 & 200,0 & 80,5 \\
\hline DQO & 7188,0 & 4083,0 & 1083,0 & 84,9 & 6855,0 & 2883,0 & 1133,0 & 83,5 \\
\hline SST & 3069,1 & 1348,0 & 232,8 & 92,4 & 5450,3 & 1021,0 & 363,0 & 93,3 \\
\hline AyG & 323,4 & 55,5 & 21,5 & 93,4 & 224,5 & 27,0 & 14,0 & 93,8 \\
\hline NTK & 360,7 & 265,4 & 137,7 & 61,8 & 388,6 & 267,4 & 158,3 & 59,3 \\
\hline Turbidez & 3165,0 & 368,0 & 11,8 & 99,6 & 4470,0 & 97,2 & 25,9 & 99,4 \\
\hline Sulfuros & 26,3 & 5,5 & 1,6 & 93,9 & 15,5 & 1,4 & 1,0 & 93,5 \\
\hline SS & N.D. & N.D. & N.D. & - & N.D. & N.D. & N.D. & - \\
\hline Cloruros & 17582,0 & 17590,4 & 17547,3 & - & 23906,6 & 24057,5 & 23971,3 & - \\
\hline EC & 37,9 & 38,4 & 38,1 & - & 51,9 & 53,3 & 52,7 & - \\
\hline
\end{tabular}

\section{Análisis estadísticos de los resultados}

Para los parámetros evaluados: DQO, SST, NTK y turbidez; en la determinación del pH óptimo de precipitación con hidróxido de potasio, y en la dosis óptima de aluminio para los efluentes del remojo convencional y el enzimático, según el análisis de ANOVA al menos un valor de $\mathrm{pH}$ y una dosis de aluminio influyen sobre la concentración de los parámetros evaluados (el valor de significancia para cada parámetro evaluado fue menor a 0,05 por lo cual se rechaza la hipótesis de igualdad de varianzas) ${ }^{19}$. Según el análisis de Tukey realizado, los distintos tipos de $\mathrm{pH}$ y dosis óptima de aluminio generan efectos de remoción diferentes entre los parámetros evaluados, por los que estadísticamente son diferentes. Para todos los resultados obtenidos, el coeficiente de variabilidad entre las concentraciones de los parámetros analizados, resultaron menores de $25 \%$, lo que respalda la obtención de resultados homogéneos entre las repeticiones realizadas.

\section{Caracterización del lodo residual}

De los resultados obtenidos (tabla 10) se observa que el contenido de COT para los lodos de ambos remojos provenientes de la coagulación con aluminio (14,4 Conv. y 14,6 Enz.) es cercano al valor del vermicompost ${ }^{3}$; mientras que para el de precipitación con $\mathrm{KOH}$ el valor (29,3 Conv. y 24,9 Enz.) es casi tres veces lo recomendado ${ }^{3}$. En la tabla 10 se puede observar que el contenido de nitrógeno para ambos tipos de lodos se encuentra cercano al valor del vermicompost ${ }^{3}$; mientras que el contenido de fósforo es mayor en el lodo de la precipitación con KOH del remojo convencional $(1,44)$. Para los demás casos, se encuentra por debajo del valor del vermicompost ${ }^{3}$. El contenido de potasio es mucho mayor para todos los tipos de lodos generados (tabla 10).

Debido a la conservación de la piel con sal industrial, el lodo residual tiene alto contenido de sal, ya que proviene de un efluente con una concentración de $\mathrm{NaOH}$ mayor a $20 \mathrm{mg} / \mathrm{L}$ (tabla 5), lo cual no lo hace viable como buen fertilizante, a pesar de su alto contenido en nutrientes 
y compuestos orgánicos. Si se utilizase un tipo de conservación que no implique la adición de sodio, tal como preservación de pieles por refrigeración o el uso de pieles frescas, estos lodos podrían ser usados como fertilizante.

Tabla 9. Caracterización de lodo residual

\begin{tabular}{|c|c|c|c|c|c|c|}
\hline \multirow[b]{2}{*}{ Parámetro } & \multirow[b]{2}{*}{ Unid. } & \multirow[b]{2}{*}{ Vermicompost $^{3}$} & \multicolumn{2}{|c|}{ Remojo Conv. } & \multicolumn{2}{|c|}{ Remojo Enz. } \\
\hline & & & $\begin{array}{c}\text { Precip. } \\
\mathrm{KOH}\end{array}$ & $\begin{array}{c}\text { Precip. } \\
\text { Al }\end{array}$ & $\begin{array}{c}\text { Precip. } \\
\mathrm{KOH}\end{array}$ & $\begin{array}{c}\text { Precip. } \\
\text { Al }\end{array}$ \\
\hline Humedad & $\%$ & - & 93,50 & 94,80 & 94,00 & 96,00 \\
\hline Ceniza & $\% \mathrm{MS}$ & - & 46,80 & 71,20 & 51,80 & 67,20 \\
\hline COT & $\% \mathrm{MS}$ & $9,97-10,62$ & 29,30 & 14,40 & 24,90 & 14,60 \\
\hline $\mathrm{N}$ & $\% \mathrm{MS}$ & 1,80 & 2,30 & 2,80 & 2,30 & 3,10 \\
\hline $\mathrm{C} / \mathrm{N}$ & - & - & 12,70 & 5,20 & 10,60 & 4,80 \\
\hline $\mathrm{P}_{2} \mathrm{O}_{5}$ & $\%$ & 0,90 & 1,44 & 0,26 & 0,76 & 0,18 \\
\hline $\mathrm{K}_{2} \mathrm{O}$ & $\%$ & 0,40 & 1,94 & 3,20 & 2,51 & 2,80 \\
\hline
\end{tabular}

\section{CONCLUSIONES}

El efluente mezcla del remojo alternativo con enzimas presenta mayor carga contaminante que el efluente mezcla del remojo convencional con químicos, debido a la mayor acción limpiadora y más eficiente remojo de pieles generada por la enzima Tanzyme RD04 en comparación con los otros químicos. Sin embargo, el remojo enzimático usa $20 \%$ menos de agua que el remojo químico, es decir, el efluente tiene ligeramente más carga pero su volumen es menor. Se obtuvieron remociones muy altas en el sistema de tratamiento aplicado a los efluentes de ambos remojos. Para ambos tipos de remojo, el pH óptimo de precipitación con hidróxido de potasio es de 12 y la dosis de coagulante sulfato de aluminio es de $800 \mathrm{mg} / \mathrm{L}$. El contenido orgánico del lodo es alto, si se utilizara un método alternativo a la preservación de pieles con cloruro de sodio, el lodo podría tener un uso como fertilizante.

\section{AGRADECIMIENTO}

Se agradece al Fondo de Investigación y Desarrollo para la Competitividad (FIDECOM) que por medio de los Proyectos de Innovación Productiva para Empresas Individuales (PIPEI) y el Convenio $\mathrm{N}^{\circ} 022-$ FINCYT-FIDECOM-PIPEI-2012, entre la empresa HELIANTHUS S.A.C y el Centro de Investigación en Química, Toxicología y Biotecnología Ambiental (CIQTOBIA) del Departamento Académico de Química de la UNALM, financiaron la investigación. 


\section{REFERENCIAS BIBLIOGRÁFICAS}

1. Hoinacki E, Moreira M, Kiefer C. Manual básico de processamento de couro. Porto Alegre: Ed. SENAI/RS; 1994.

2. Centro de Promoción de Tecnologías Sostenibles (CPTS). Guía Técnica de Producción más limpia para curtiembres. 1ra ed. La Paz: CPTS; 2003.

3. Das C, DasGupta S, De S. Treatment of soaking effluent from a tannery using membrane separation processes. Desalination. 2007;216(1-3):160-73.

4. Soares A, Guieysse B, Jefferson B, Cartmell E, Lester JN. Nonyphenol in the environment: A critical review on occurrence, fate, toxicity and treatment in wastewaters. J Environ Int. 2008; 34: 1033-1049.

5. Souza F, Guterres M. Application of enzymes in leather processing: a comparison between chemical and coenzymatic processes. Braz J Chem Eng. 2012; 29 (3): 473-482.

6. Herrmann L. Enzimas no proceso de Industrialização do Couro. Revista do Couro. 2006; 186: 92-94.

7. Kaul SN, Nandy Tapas, Szpyrkowicz L, Gautam A, Khanna DR. Wastewater management with special reference to tanneries. New Delhi: Discovery Publishing House; 2005.

8. Kbdasli I, Ölmez T, Tüng O. Nitrogen removal from tannery wastewater by protein recovery. Water Sci Technol. 2003; 48: 215-223.

9. Cerón P. Estudio de un sistema físico-químico a escala prototipo de tratamiento de aguas residuales provenientes de una curtiembre [Tesis de pregrado]. Quito: Universidad San Francisco de Quito; 2011.

10. Haydar S, Aziz J. Characterization and treatability studies of tannery wastewater using chemically enhanced primary treatment (CEPT). A case study of Saddiq Leather Works. J Hazard Mater. 2009; 163: 1076-1083.

11. Bornhardt C, Vidal G y Torres M. Reducción del impacto ambiental generado por efluentes de la industria de curtiembre. XXVII Congreso Interamericano de Engenharia Sanitárie e Ambiental; 3-8 nov 2000; Porto Alegre-Brasil.

12. Méndez R, Vidal G., Lorber K, Márquez F. Producción limpia en la industria de curtiembre. Compostela: Ediciones Servicio de Publicacións e Intercambio Científico da USC; 2007.

13. Lefebvre O, Vasudevan N, Torrijosa M, Thanasekaran K y Moletta R. Anaerobic digestion of tannery soak liquor with an aerobic post-treatment. J Water Res. 2006; 40: 1492-1500.

14. Ilou I, Souabi S y Digua K. 2012. Quantification of Pollution Discharges from Tannery Wastewater and Pollution Reduction by Pre-Treatment Station. Int J Sci Res. 2012; 3(5):1706-1715.

15. Iyappan K, Boopathy R, Suguna L, Ranganathan, N. y Vedaraman, N. Electro-oxidación of tannery soak water using solar photovoltaic stand-alone systems. J Acad Indus. 2012; 4:2278-5213.

16. Miller S, Gagnet A y Worde R. Reporte Técnico para la Industria de Curtiembres en el Perú. Informe para el Ministerio de Industria, Turismo, Integración y Comercio Internacional (MITINCI). 1999.

17. Mijaylova P, Moeller G y Juárez M. Alternative treatment strategy for tannery water 
reuse and material recovery. Water Sci Techonol. 2014. 50 (2):121-130.

18. Córdova H. Minimización de emisiones de cromo en el proceso de curtido, por uso de complejantes y basificantes de cromo y tratamiento de efluentes. [Tesis de pregrado]. Lima: Universidad Nacional Agraria La Molina. 2014.

19. Salkind N. Métodos de investigación. México D.F.: Prentice Hall; 1999: 225-226. 